Pacific Journal of Mathematics

GROUPS OF *-AUTOMORPHISMS AND INVARIANT MAPS OF

KAZUYUKI SATE 


\title{
GROUPS OF *-AUTOMORPHISMS AND INVARIANT MAPS OF VON NEUMANN ALGEBRAS
}

\author{
KAZUYUKI SAITô
}

\begin{abstract}
Let $M$ be a von Neumann algebra and let $G$ be a group acting on $M$ by *-automorphisms of $M . M$ is $G$-finite if for every nonnegative element $a$ in $M$ with $a \neq 0$, there exists a $G$-invariant normal state $\phi$ such that $\phi(a) \neq 0$. The main result in this paper asserts that $M$ is $G$-finite if and only if for every weakly relatively compact subset $K$ of the predual of $M$, the orbit of $K$ under $G$ is also weakly relatively compact.
\end{abstract}

Given a noncommutative dynamical system, that is, pairs $(M, G)$ where $M$ is a von Neumann algebra and $G$ is a group of *-automorphisms of $M$, one can ask whether or not there are sufficiently many $G$-invariant normal states (we call such a case that $(M, G)$ is $G$-finite [9])?

First result along these lines is due to I. Kovacs and J. Szücs [9] who obtained that $(M, G)$ is $G$-finite if and only if there is a $G$-invariant faithful normal projection of norm one from $M$ onto the fixed subalgebra $M^{G}$ under $G$ (see also $[11,14]$ ).

Recently, using results of Akemann [1] and Takesaki [15] concerning the predul of a von Neumann algebra, together with the Ryll-Nardzewski fixed point theorem ([5, 10]), F. J. Yeadon gave an elegant proof of the existence of a trace in a finite von Neumann algebra [16].

In this paper, we will give a Banach space like characterization of the $G$-finiteness of $(M, G)$ using weakly relatively compact subsets of the predual $M_{*}$ of $M$ which is a noncommutative extension of a theorem of Hajian and Kakutani $([7,8])$ and in case where $G$ is the inner automorphisms of $M$, includes the result of F.J. Yeadon (see also [16]). The result in this paper can be easily extended to groups of identity preserving isometries of $M$.

2. Notations and a statement of a theorem. Let $(M, G)$ be a noncommutative dynamical system and $M_{*}$ be the predual of $M$, that is, the Banach space of all bounded normal (or $\sigma$-weakly continuous) linear functionals on $M([3,12])$. Let $\left(T_{g} \varphi\right)(a)=\varphi\left(a^{g}\right), a \in M, g \in G$ and $\varphi \in M_{*}$, then $T_{g}$ is a linear isometry of $M_{*}$ onto $M_{*}$. We say that $(M, G)$ is $G$-finite if $M$ has sufficiently many normal states in the sense that for every nonnegative element $a$ in $M$ with $a \neq 0$, there exists a $G$-invariant normal state $\phi\left(\right.$ that is, $\left.T_{g} \phi=\phi, g \in G\right)$ such that $\phi(a) \neq 0$. 
Now we state our main theorem.

THEOREM. Let $(M, G)$ be a noncommutative dynamical system, then $(M, G)$ is $G$-finite if and only if for every weakly relatively compact (w.r.c.) subset $K$ of $M_{*}$, the orbit of $K$ under $G$, that is, the set $\left\{T_{g} \phi ; g \in G, \phi \in K\right\}$ is also w.r.c.

3. Proof of Theorem. "If" part of Theorem is valid under a weaker assumption, more precisely to say that if for every $\phi$ in $M_{*}$ with $\phi \geqq 0,\left\{T_{g} \phi ; g \in G\right\}$ is w.r. c., then $(M, G)$ is $G$-finite. However, this is an easy consequence of lemma in [14] (see also [11]). To prove the converse, we need the following lemma which concerns with the continuity of the map $(\Phi, \omega) \rightarrow \omega \circ \Phi$ from $L_{*}(M) \times M_{*} \rightarrow M_{*}$ where $L_{*}(M)$ is the $\sigma$-weakly continuous bounded linear maps of $M$ into $M$ equipped with the weak operator topology and $M_{*}$ has the $W^{*}$-topology. For the later discussions, we state it in the following form.

Lemma 1. Let $N$ be a von Neumann algebra with a set $H$ of normal *-homomorphisms of $N$ into $N$. Suppose that for every $\phi$ $N_{*}$ (the predual of $N$ ) with $\phi \geqq 0$, and every sequence $\left\{b_{n}\right\}$ in the nonnegative part of the unit sphere $S$ of $N$ such that $b_{n} \rightarrow 0$ ( $\sigma$-weakly), $\phi\left(\Phi\left(b_{n}\right)\right) \rightarrow 0(n \rightarrow \infty)$ uniformly for $\Phi \in H$. Let $\left\{\phi_{n}\right\}$ be a sequence in $N_{*}$ which converges weakly to some $\phi_{0}$ in $N_{*}$ and $\left\{a_{n}\right\}$ be a sequence of self-adjoint element in $S$ which converges strongly to 0 , then $\phi_{j}\left(\Phi\left(a_{n}\right)\right) \rightarrow 0(n \rightarrow \infty)$ uniformly not only for $\Phi \in H$ but also for $j$.

Proof. Observe first that the $\sigma$-weak topology restricted on $S$ is a compact Hausdorff topology with the neighborhood basis which consists of all possible sets $\left\{a ; a \in S,\left|\psi_{i}(a)-\psi_{i}\left(a_{0}\right)\right|<\varepsilon, i=1,2, \cdots, n\right\}$ with $a_{0} \in S, \varepsilon>0$ (real number) and $\psi_{i} \in N_{*}\left(\psi_{i} \geqq 0\right)$. Let $H_{i}=\{a \in S$; $\left|\left(\phi_{j}-\phi_{0}\right)(a)\right| \leqq \varepsilon$ for all $\left.j \geqq i\right\}$, then $H_{i}$ is $\sigma$-weakly closed subset of $S$ for each $i$ and $S=\bigcup_{i=1}^{\infty} H_{i}$. Now Baire's category theorem says that there are a natural numbers $i(0), m$, an element $a_{0}$ in $S$ and $\psi_{i}(i=1,2, \cdots, m)$ in $N_{*}$ with $\psi_{i} \geqq 0$ for all $i$ such that

$$
\bigcap_{i=1}^{m}\left\{a ; a \in S ;\left|\psi_{i}(a)-\psi_{i}\left(a_{0}\right)\right|<1\right\} \subset H_{i(0)} \text {. }
$$

Since $a_{n} \rightarrow 0(n \rightarrow \infty)$ strongly, by the spectral theorem, for any given positive number $\varepsilon$, there is a sequence $\left\{e_{n}\right\}$ of projections in $M$ such that $e_{n} \rightarrow 1$ (strongly) and $\left\|a_{n} e_{n}\right\| \leqq \varepsilon / 6$ for each $n$. By the uniform boundedness theorem, we may assume that $\operatorname{Sup}_{j}\left\{\left\|\phi_{j}\right\|,\left\|\phi_{0}\right\|\right\}=1$ without loss of generality. For each $\Phi \in H$, we have $\left\|\Phi\left(e_{n} a_{n} e_{n}\right)\right\| \leqq$ $\left\|a_{n} e_{n}\right\| \leqq \varepsilon / 6,\left\|\Phi\left(e_{n} a_{n}\left(1-e_{n}\right)\right)\right\| \leqq\left\|a_{n} e_{n}\right\| \leqq \varepsilon / 6$ and $\left.\| \Phi\left(\left(1-e_{n}\right) a_{n} e_{n}\right)\right) \| \leqq$ 
$\left\|a_{n} e_{n}\right\| \leqq \varepsilon / 6$ for each $n$. Thus we have

$$
\begin{aligned}
\left|\left(\phi_{j}-\phi_{0}\right)\left(\Phi\left(a_{n}\right)\right)\right| \leqq & \left|\left(\phi_{j}-\phi_{0}\right)\left(\Phi\left(e_{n} a_{n} e_{n}\right)\right)\right| \\
& +\left|\left(\phi_{j}-\phi_{0}\right)\left(\Phi\left(e_{n} a_{n}\left(1-e_{n}\right)\right)\right)\right| \\
& +\left|\left(\phi_{j}-\phi_{0}\right)\left(\Phi\left(\left(1-e_{n}\right) a_{n} e_{n}\right)\right)\right| \\
& +\left|\left(\phi_{j}-\phi_{0}\right)\left(\Phi\left(\left(1-e_{n}\right) a_{n}\left(1-e_{n}\right)\right)\right)\right| \\
\leqq & \varepsilon+\left|\left(\phi_{j}-\phi_{0}\right)\left(\Phi\left(\left(1-e_{n}\right) a_{n}\left(1-e_{n}\right)\right)\right)\right|
\end{aligned}
$$

Put $b_{n}(\Phi)=\Phi\left(\left(1-e_{n}\right) a_{n}\left(1-e_{n}\right)\right)+\Phi\left(e_{n}\right) a_{0} \Phi\left(e_{n}\right)$, then, since $b_{n}(\Phi)-$ $a_{0}=\left(1-\Phi\left(e_{n}\right)\right) \Phi\left(a_{n}\right)\left(1-\Phi\left(e_{n}\right)\right)-\left(1-\Phi\left(e_{n}\right)\right) a_{0} \Phi\left(e_{n}\right)-\Phi\left(e_{n}\right) a_{0}\left(1-\Phi\left(e_{n}\right)\right)-$ $\left(1-\Phi\left(e_{n}\right)\right) a_{0}\left(1-\Phi\left(e_{n}\right)\right)$, we have, by Schwarz' inequality,

$$
\left|\psi_{j}\left(b_{n}(\Phi)-a_{0}\right)\right| \leqq \psi_{i}\left(\Phi\left(1-e_{n}\right)\right)+3\left\|\psi_{i}\right\| \psi_{i}\left(\Phi\left(1-e_{n}\right)\right)^{1 / 2} .
$$

Similarly, we have

$$
\left|\psi_{j}\left(\Phi\left(e_{n}\right) a_{0} \Phi\left(e_{n}\right)-a_{0}\right)\right| \leqq \psi_{i}\left(\Phi\left(1-e_{n}\right)\right)+2\left\|\psi_{i}\right\| \psi_{i}\left(\Phi\left(1-e_{n}\right)\right)^{1 / 2} .
$$

Since, by the assumption, $\psi_{i}\left(\Phi\left(1-e_{n}\right)\right) \rightarrow 0(n \rightarrow \infty)$ uniformly for $\Phi \in H$ and $i=1,2, \cdots, m$, we can choose a natural number $n(\varepsilon)$ (depends only on $\varepsilon$ ) such that $b_{n}(\Phi), \Phi\left(e_{n}\right) a_{0} \Phi\left(e_{n}\right) \in H_{i(0)}$ for all $n \geqq n(\varepsilon)$. Thus, we have

$$
\left|\left(\phi_{j}-\phi_{0}\right)\left(\Phi\left(\left(1-e_{n}\right) a_{n}\left(1-e_{n}\right)\right)\right)\right|<2 \varepsilon
$$

for all $j \geqq i(0)$, all $\Phi \in H$ and all $n \geqq n(\varepsilon)$. Since, for each $j(j=$ $1,2, \cdots, i(0)-1)$

$$
\begin{aligned}
\left|\left(\phi_{j}-\phi_{0}\right)\left(\Phi\left(a_{n}\right)\right)\right| & =|| \phi_{j}-\phi_{0}\left|\left(\Phi\left(a_{n}\right) v_{j}\right)\right| \\
& \leqq\left.\left\{\left|\phi_{j}-\phi_{0}\right|\left(\left\{\Phi\left(a_{n}\right)\right\}^{2}\right)\right\}^{1 / 2}\left\|\phi_{j}-\phi_{0}\right\|\right|^{1 / 2} \\
& \leqq 2^{1 / 2}\left\{\left|\phi_{j}-\phi_{0}\right|\left(\Phi\left(a_{n}^{2}\right)\right)\right\}^{1 / 2}
\end{aligned}
$$

and

$$
\left|\phi_{0}\left(\Phi\left(a_{n}\right)\right)\right|=|| \phi_{0}\left|\left(\Phi\left(a_{n}\right) v\right)\right| \leqq\left\{\left|\phi_{0}\right|\left(\Phi\left(\alpha_{n}^{2}\right)\right)\right\}^{1 / 2}
$$

where $\phi_{j}-\phi_{0}=R_{v_{j}}\left|\phi_{j}-\phi_{0}\right|$ (resp. $\left.\phi_{0}=R_{v}\left|\phi_{0}\right|\right)$ is the polar decomposition of $\phi_{j}-\phi_{0}\left(\right.$ resp. $\left.\phi_{0}\right)([12]), a_{n}^{2} \rightarrow 0$ weakly implies, by the assumption, that there is a positive integer $n(\varepsilon)^{\prime}$ (depending only on $\varepsilon$ ) such that $\left|\left(\phi_{j}-\phi_{0}\right)\left(\Phi\left(a_{n}\right)\right)\right|<\varepsilon$ and $\left|\phi_{0}\left(\Phi\left(a_{n}\right)\right)\right|<\varepsilon$ for all $\Phi \in H, j=$ $1,2, \cdots, i(0)-1$ and all $n \geqq n(\varepsilon)^{\prime}$.

Combining the above estimations, we have

$$
\left|\phi_{j}\left(\Phi\left(a_{n}\right)\right)\right|<4 \varepsilon \text { for all } n \geqq \max \left(n(\varepsilon), n(\varepsilon)^{\prime}\right) \text {, all } j
$$

and all $\Phi \in H$. This completes the proof of Lemma 1 .

Before going into the proof of theorem, we prepare the following: 
LEMmA 2. Keep the notations in theorem. If $(M, G)$ is G-finite, then, for every sequence $\left\{a_{n}\right\}$ of nonnegative elements in the unit sphere $S$ of $M$ which converges weakly to 0 , and every $\phi$ in $M_{*}$, $\left(T_{g} \phi\right)\left(a_{n}\right) \rightarrow 0$ uniformly for $g \in G$.

Proof. If not, there exists a positive number $\varepsilon_{0}$ such that for each positive integer $n$, we can choose a positive integer $k(k(n) \uparrow \infty)$ and $g(n) \in G$ such that

$$
\left|T_{g(n)} \phi\left(a_{k(n)}\right)\right| \geqq \varepsilon_{0} \text {. }
$$

Put $a_{k(n)}=b(n)$ then since $\left\{\left(b(n)^{g(n)}\right\}\right.$ is a $\sigma$-weakly relatively compact subset of $S \cap M^{+}$(where $M^{+}$is the positive portion of $M$ ), there is a $\sigma$-weakly cluster point $a(a \geqq 0)$ of $\left\{\left(b(n)^{g(n)}\right\}\right.$. Thus for every positive number $\delta$, every $G$-invariant normal state $\rho$ and every positive integer $n$, there is a natural number $i(n)(i(n)>n$ and $i(n) \uparrow \infty)$ such that

$$
\left.\mid \rho(a)-\rho(b(n))^{g(i(n))}\right) \mid<\delta \quad n=1,2, \cdots .
$$

Since $\rho$ is $G$-invariant, $\rho\left(\left(b(i(n))^{g(i(n))}\right)=\rho(b(i(n))) \rightarrow 0(i(n) \rightarrow \infty)\right.$. Thus $|\rho(a)| \leqq \delta$ for every $\delta$ and the $G$-finiteness of $(M, G)$ implies $a=0$. Hence this contradicts with the inequality $(*)$. Thus $\left(T_{g} \phi\right)\left(a_{n}\right) \rightarrow$ $0(n \rightarrow \infty)$ uniformly for $g \in G$ and the proof is completed.

Proof of Theorem. Suppose $(M, G)$ is $G$-finite. We will prove that for every w.r.c. subset $K$ of $M_{*}$, $\left\{T_{g} \phi ; \phi \in K g \in G\right\}$ is also w.r.c. To prove this, we have only to show that for every orthogonal sequence $\{e(n)\}$ of projections, $\lim _{n \rightarrow \infty} T_{g} \phi(e(n))=0$ uniformly for $g \in G$ and $\phi \in K$. If not, there is a positive number $\varepsilon$ such that for each positive integer $k$, there are a natural number $n(k)(n(k) \uparrow \infty), g(k) \in G$ and $\phi_{k} \in K$ such that

$$
\left|T_{g(k)} \phi_{k}(e(n(k)))\right| \geqq \varepsilon .
$$

By Eberlein-ŠSmulian's theorem ([4]), there is a subsequence $\left\{\phi_{k(p)}\right\}$ of $\left\{\phi_{k}\right\}(k(p) \uparrow \infty)$ such that $\phi_{k(p)} \rightarrow \phi_{0}$ weakly $(p \rightarrow \infty)$ for some $\phi_{0}$ in $M_{*}$. Now $e(n(k(p))) \rightarrow 0(p \rightarrow \infty)$ strongly, which implies by Lemma 2 and Lemma 1, that $\mid T_{g(k(p))} \phi_{k(p)}(e(n(k(p))) \mid \rightarrow 0(p \rightarrow \infty)$ and this contradicts with the inequality $(* *)$. This completes the proof of theorem.

4. Remarks. Theorem is a generalization of [11]. We should remark that the result of theorem can be easily extended to groups of Jordan Automorphisms of $M$. [13] When $G$ is a semi-group of normal Jordan homomorphisms ([13]) of $M$ into $M$, by an easy modification of Lemma 1 and Lemma 2, "only if" part of theorem is valid, 
however, as the following example shows, the converse assertion does not hold in general, even if $G$ is a semi group of *-isomorphisms of $M$ into $M$.

Let $M=L^{\infty}([0,1))$ be the abelian von Neumann algebra of essentially bounded complex-valued functions on $[0,1)$ with respect to Lebesque measure $\mu$. Let us consider two measurable transformations $g_{1}$ and $g_{2}$ defined as follows $([2,8]): g_{1}(\omega)=3 \omega(\bmod 1), \omega \in[0,1), g_{2}(\omega)=$ $2 \omega+1 / 3($ resp. $=(\omega-1 / 3) / 2, \omega \in[0,1 / 3)($ resp. $\omega \in[1 / 3,1))$. For each $f \in M$, let $\left(\Phi_{1} f\right)(\omega)=f\left(g_{1} \omega\right), \omega \in[0,1)$ and $\left(\Phi_{2} f\right)(\omega)=f\left(g_{2}(\omega), \omega \in[0,1)\right.$. Let $H$ be the semi-group of normal *-homomorphisms of $M$ into $M$ generated by $\Phi_{1}$ and $\Phi_{2}$. Then by [2] and [8], we can easily check that for each $\phi \in M_{*}\left(=L^{1}([0,1))\right),\{\phi \circ \Phi, \Phi \in H\}$ is w.r. c.. Thus by [6] and Lemma 1 , for every w.r.c. subset $K$ of $M_{*},\{\dot{\phi} \circ \Phi, \Phi \in H, \dot{\phi} \in K\}$ is also W.r.c. However, since $g_{1}$ is ergodic with respect to $\mu$ and $\mu$ is not invariant under $g_{2},(M, H)$ has no $H$-invariant functionals in $M_{*}$.

The above example implies that the Ryll-Nardzewski fixed point theorem is not valid in general without the assumption of distal action of $H$.

\section{REFERENCES}

1. C. A. Akemann, The dual space of an operator algebra, Trans. Amer. Math. Soc., 126 (1967), 286-302.

2. J.R. Blum and N. Friedman, On invariant measures for classes of transformations, Z. Wahrschein. verw. Geb., 8 (1967), 301-305.

3. J. Dixmier, Les algèbres d'opérateurs dans l'espace hilbertien, Gauthier-Villars, Paris, 1969.

4. N. Dunford and J. T. Schwartz, Linear Operators 1, Interscience, New York, 1963.

5. F.P. Greenleaf, Invariant Means on Topological Groups, Van Nostrand, New York, 1969.

6. A. Grothendieck, Sur les applications lineaires faiblement compacts d'espaces du type $C(K)$, Canad. J. Math., 5 (1953), 129-173.

7. A. B. Hajian and S. Kakutani, Weakly wandering sets and invariant measures, Trans. Amer. Math. Soc., 110 (1964), 136-151.

8. A. B. Hajian and Y. Itô, Weakly wandering sets and invariant measures for a group of transformatiions, J. Math. and Mech., 18 (1969), 1203-1216.

9. I. Kovacs and J. Szücs, Ergodic type theorems in von Neumann algebras, Acta Sci. Math. (Szeged), 27 (1966), 233-246.

10. I. Namioka and E. Asplund, A geometric proof of Ryll-Nardzewsti's fixed point theorem, Bull. Amer. Math. Soc., 73 (1967), 443-445.

11. K. Saitô, Automorphism groups of von Neumann algebras and ergodic type theorems, Acta Sci. Math. (Szeged), 36 (1974), 119-130.

12. S. Sakai, $C^{*}$-algebras and $W^{*}$-algebras, Springer, Berlin, Heidelberg, New York, 1971.

13. E. Størmer, On the Jordan structures of $C^{*}$-algebras, Trans. Amer. Math. Soc., 120 (1965), 438-447.

14. - Invariant states of von Neumann algebras, Math. Scand., 30 (1972), $253-256$. 
15. M. Takesaki, On the conjugate space of an operator algebra, Tôhoku Math. J., 10 (1958), 194-203.

16. F.J. Yeadon, $A$ new proof of the existence of a trace in a finite von Neumann algebra, Bull. Amer. Math. Soc., 77 (1971), 257-260.

Received March 4, 1974 and in revised form March 3, 1975. The author is partially supported by The Sakkokai Foundation.

TôHOKU UNIVERSITY 


\section{PACIFIC JOURNAL OF MATHEMATICS}

\section{EDITORS}

RICHARD ARENS (Managing Editor)

University of California

Los Angeles, California 90024

\section{J. DugundJI}

Department of Mathematics University of Southern California Los Angeles, California 90007

D. Gilbarg and J. Milgram

Stanford University

Stanford, California 94305
University of Washington Seattle, Washington 98105

\section{ASSOCIATE EDITORS}
E. F. BECKENBACH
B. H. NeumanN
F. WolF
K. YoShIDA

\section{SUPPORTING INSTITUTIONS}

\author{
UNIVERSITY OF SOUTHERN CALIFORNIA \\ STANFORD UNIVERSITY \\ UNIVERSITY OF TOKYO \\ UNIVERSITY OF UTAH \\ WASHINGTON STATE UNIVERSITY \\ UNIVERSITY OF WASHINGTON \\ $\stackrel{*}{*} \stackrel{*}{*} \stackrel{*}{ }{ }^{*}$ AMERICAN MATHEMATICAL SOCIETY
}

The Supporting Institutions listed above contribute to the cost of publication of this Journal, but they are not owners or publishers and have no responsibility for its content or policies.

Mathematical papers intended for publication in the Pacific Journal of Mathematics should be in typed form or offset-reproduced, (not dittoed), double spaced with large margins. Underline Greek letters in red, German in green, and script in blue. The first paragraph or two must be capable of being used separately as a synopsis of the entire paper. Items of the bibliography should not be cited there unless absolutely necessary, in which case they must be identified by author and Journal, rather than by item number. Manuscripts, in triplicate, may be sent to any one of the editors. Please classify according to the scheme of Math. Reviews, Index to Vol. 39. All other communications should be addressed to the managing editor, or Elaine Barth, University of California, Los Angeles, California, 90024.

The Pacific Journal of Mathematics expects the author's institution to pay page charges, and reserves the right to delay publication for nonpayment of charges in case of financial emergency.

100 reprints are provided free for each article, only if page charges have been substantially paid. Additional copies may be obtained at cost in multiples of 50 .

The Pacific Journal of Mathematics is issued monthly as of January 1966. Regular subscription rate: $\$ 72.00$ a year (6 Vols., 12 issues). Special rate: $\$ 36.00$ a year to individual members of supporting institutions.

Subscriptions, orders for back numbers, and changes of address should be sent to Pacific Journal of Mathematics, 103 Highland Boulevard, Berkeley, California, 94708.

\section{PUBLISHED BY PACIFIC JOURNAL OF MATHEMATICS, A NON-PROFIT CORPORATION}

Printed at Kokusai Bunken Insatsusha (International Academic Printing Co., Ltd.), 270, 3-chome Totsuka-cho, Shinjuku-ku, Tokyo 160, Japan.

\section{Copyright (C) 1975 by Pacific Journal of Mathematics} Manufactured and first issued in Japan 


\section{Pacific Journal of Mathematics}

\section{Vol. 57, No. $2 \quad$ February, 1975}

Norman Larrabee Alling, On Cauchy's theorem for real algebraic curves with boundary .......

Daniel D. Anderson, A remark on the lattice of ideals of a Prüfer domain ..................

Dennis Neal Barr and Peter D. Miletta, A necessary and sufficient condition for uniqueness of

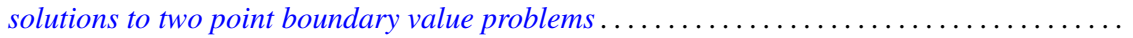

Ladislav Beran, On solvability of generalized orthomodular lattices . . . . . . . . . . ........

L. Carlitz, A three-term relation for some sums related to Dedekind sums . . . . . . . . . .....

Arthur Herbert Copeland, Jr. and Albert Oscar Shar, Images and pre-images of localization

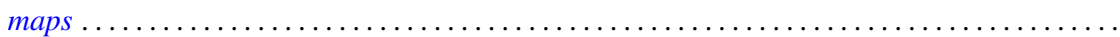

G. G. Dandapat, John L. Hunsucker and Carl Pomerance, Some new results on odd perfect

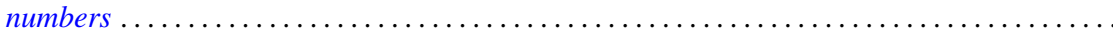

M. Edelstein and L. Keener, Characterizations of infinite-dimensional and nonreflexive

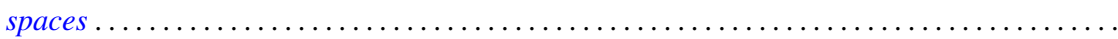

Francis James Flanigan, On Levi factors of derivation algebras and the radical embedding

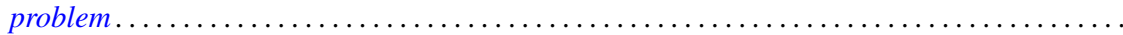

Harvey Friedman, Provable equality in primitive recursive arithmetic with and without

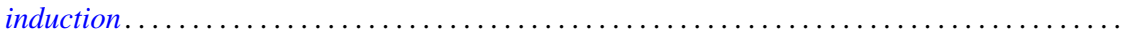

Joseph Braucher Fugate and Lee K. Mohler, The fixed point property for tree-like continua with

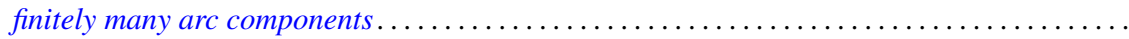

John Norman Ginsburg and Victor Harold Saks, Some applications of ultrafilters in

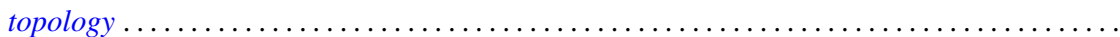

Arjun K. Gupta, Generalisation of a "square" functional equation .....................

Thomas Lee Hayden and Frank Jones Massey, Nonlinear holomorphic semigroups ..........

V. Kannan and Thekkedath Thrivikraman, Lattices of Hausdorff compactifications of a locally

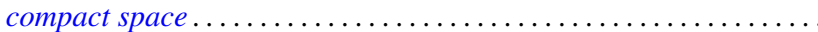

J. E. Kerlin and Wilfred Dennis Pepe, Norm decreasing homomorphisms between group

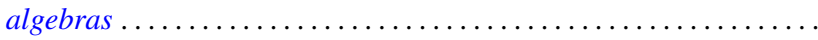

Young K. Kwon, Behavior of $\Phi$-bounded harmonic functions at the Wiener boundary ...

Richard Arthur Levaro, Projective quasi-coherent sheaves of modules .

Chung Lin, Rearranging Fourier transforms on groups...........................

David Lowell Lovelady, An asymptotic analysis of an odd order linear differential equation . . 4475

Jerry Malzan, On groups with a single involution .......................... 481

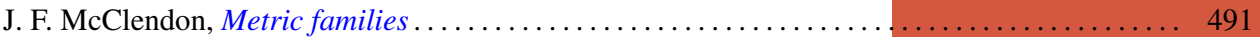

Carl Pomerance, On multiply perfect numbers with a special property .

Mohan S. Putcha and Adil Mohamed Yaqub, Polynomial constraints for finiteness of semisimple rings. .

Calvin R. Putnam, Hyponormal contractions and strong power convergence . . . . . . . . . 531

Douglas Conner Ravenel, Multiplicative operations in $\mathrm{BP} * \mathrm{BP} \ldots \ldots \ldots \ldots \ldots \ldots \ldots \ldots \ldots .539$

Judith Roitman, Attaining the spread at cardinals which are not strong limits . . . . . . . . . 545

Kazuyuki Saitô, Groups of *-automorphisms and invariant maps of von Neumann algebras . . . 553

Brian Kirkwood Schmidt, Homotopy invariance of contravariant functors acting on smooth

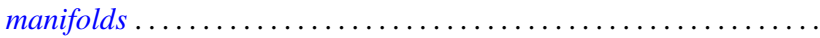

Kenneth Barry Stolarsky, The sum of the distances to $N$ points on a sphere.

Mark Lawrence Teply, Semiprime rings with the singular splitting property.

J. Pelham Thomas, Maximal connected Hausdorff spaces..............

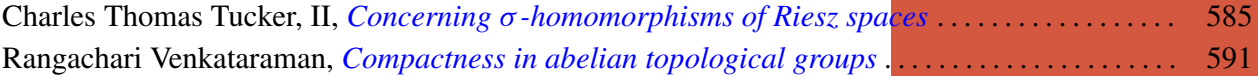

William Charles Waterhouse, Basically bounded functors and flat sheaves . . . . . . . . . . . 597

David Westreich, Bifurcation of operator equations with unbounded linearized part ......... 611

William Robin Zame, Extendibility, boundedness and sequential convergence in spaces of 